\title{
Permanência e Êxito Escolar: análise do desempenho acadêmico de estudantes ingressantes no ensino médio integrado do IFRN/Caicó através das cotas étnico-raciais no ano de 2014
}

Stay and School Success: analysis of the academic performance of students entering the integrated high school of IFRN/Caicó through ethnic-racial quotas in 2014

Séjour et Réussite Scolaire: analyse des résultats scolaires des élèves entrant au lycée intégré IFRN/Caicó à travers des quotas ethno-raciaux en 2014

Kelson Gérison Oliveira Chaves ${ }^{1}$ Instituto Federal do Rio Grande do Norte

Sandra Maria de Assis $^{2}$ Instituto Federal do Rio Grande do Norte

Heloísa Medeiros de Araújo ${ }^{3}$ Universidade Federal do Rio Grande do Norte

Deickson Lennon Galvao de Souza ${ }^{4}$ Instituto Federal do Rio Grande do Norte

Camila Goulart de Campos ${ }^{5}$ Instituto Federal do Rio Grande do Norte

Resumo: Considerando as políticas públicas de inclusão desenvolvidas na última década no IFRN (Instituto Federal de Educação, Ciência e Tecnologia do Rio Grande do Norte), e ao mesmo tempo os preconceitos decorrentes delas, em grande parte fruto do desconhecimento dos impactos positivos que tais políticas acarretam, a pesquisa faz uma análise criteriosa do rendimento acadêmico dos alunos cotistas étnico-raciais, considerando as condições objetivas

\footnotetext{
${ }^{1}$ Doutorado pelo Programa de Pós-Graduação em Ciências Sociais pela Universidade Federal do Rio Grande do Norte (UFRN). Professor de História do Instituto Federal do Rio Grande do Norte (IFRN), campus Caicó. E-mail: kelson.oliveira@ifrn.edu.br. Lattes: http://lattes.cnpq.br/2260743286761060. ORCID: https://orcid.org/0000-0001-6756-0211.

2 Doutoranda pelo Programa de Pós-Graduação em Educação Profissional (PPGEP) do Instituto Federal do Rio Grande do Norte (IFRN). Professora de História do Instituto Federal do Rio Grande do Norte (IFRN), campus Caicó. E-mail: sandra.assis@ifrn.edu.br. Lattes: http://lattes.cnpq.br/2211024380829073. ORCID: https://orcid.org/0000-0002-9577-9656.

${ }^{3}$ Graduanda em Pedagogia pela Universidade Federal do Rio Grande do Norte (UFRN), campus Caicó. E-mail: heloisamedeirosaraujo@hotmail.com. L Lattes: http://lattes.cnpq.br/2176815463231931. ORCID: https://orcid.org/0000-0002-9425-8031.

4 Doutorando Programa de Pós-Graduação em Educação Profissional (PPGEP) do Instituto Federal do Rio Grande do Norte (IFRN). Professor de Geografia do Instituto Federal do Rio Grande do Norte (IFRN), campus Caicó. E-mail: deickson_lennon@hotmail.com. Lattes: http://lattes.cnpq.br/0694847290674145. ORCID: https://orcid.org/0000-0003-4524-2399.

${ }^{5}$ Mestre pelo Programa de Pós-Graduação em Educação Profissional (PPGEP) do Instituto Federal do Rio Grande do Norte (IFRN). Professora de Sociologia do Instituto Federal do Rio Grande do Norte (IFRN), campus Lajes. E-mail: goulart.camila@ifrn.edu.br. Lattes: http://lattes.cnpq.br/3745293433365403. ORCID: https://orcid.org/0000-0003-0262-7301.
} 
de sua permanência e de seu êxito. $O$ trabalho de pesquisa fundou-se na necessidade de compilar dados que avaliem o andamento da política de cotas e que auxiliem nas futuras proposições do IFRN, no que se refere às ações de inclusão étnico-raciais. Os resultados trazem dados em gráficos e em entrevistas, que avaliam minuciosamente a permanência e o êxito dos alunos cotistas, podendo vir a subsidiar práticas pedagógicas voltadas a entender e atender o contexto e as dificuldades do segmento dos alunos que entraram pelas cotas étnico-raciais no âmbito do IFRN, especialmente, no campus Caicó-RN.

Palavras-chave: Ações afirmativas. Alunos cotistas. Rendimento acadêmico. Inclusão social.

Abstract: Considering the public policies for social inclusion developed in the last decade, in the IFRN, and at the same time the prejudices resulting from it, due in large part, to the lack of knowledge of the positive impacts that their policies cause, the research makes a careful analysis of the academic performance of the ethno-racial quota students, taking into account the objective conditions of its permanence and success. The research started from the need to compile data that, initially, assistant the IFRN future propositions regarding the actions of ethnic-racial inclusion. The results of the research provide data, in graphs and interviews, that thoroughly evaluate the permanence and success of quota students, and may subsidize pedagogical practices aimed at understanding and attending to the context and difficulties of the segment of students who entered the ethno-racial quotas in exent of IFRN, especially, on the Caicó campus.

Keywords: Affirmative Actions. Quota Students. Academic Performance. Social Inclusion.

Résumé: Compte tenu des politiques publiques d'inclusion développées au cours de la dernière décennie, à l'Institut fédéral de l'éducation, des sciences et de la technologie de Rio Grande do Norte/IFRN, et en même temps des préjugés qui en découlent, principalement en raison du manque de connaissance des impacts positifs que ces politiques entraînent, la recherche fait une analyse minutieuse du rendement scolaire des étudiants de quota ethnique-racial, en tenant compte des conditions objectives de leur permanence et de leur réussite. Les travaux de recherche sont partis de la nécessité de compiler des données qui évaluent les progrès de la politique des quotas et appuient les propositions de l'IFRN, en ce qui concerne les actions d'inclusion ethnique et raciale. Les résultats fournissent des données, sous forme de graphiques et d'entretiens, qui évaluent de manière approfondie la permanence et le succès des étudiants de quota, et peuvent soutenir les pratiques éducatives visant à comprendre et à répondre au contexte et aux difficultés du segment des étudiants qui sont entrés par le biais de quotas ethno-raciaux en IFRN, en particulier sur le campus de Caicó-RN.

Mot clé: Actions positives. Étudiants de quota. Performance académique. L'inclusion sociale.

Recebido em: 19 abril de 2020

Aceito em: 22 de junho de 2020

\section{INTRODUÇÃO:}

Ações afirmativas devem ser entendidas como políticas que objetivam corrigir desigualdades agudas presentes numa determinada sociedade. No presente caso, estamos a apresentar um estudo 
que toma como sujeitos de pesquisa pessoas cujo ingresso no IFRN (Instituto Federal de Educação, Ciência e Tecnologia do Rio Grande do Norte) se efetivou por meio de uma ação afirmativa instituída em 2012, qual seja: a Lei n 12.711/2012 (Brasil, 2012), que reservou parte das vagas das instituições federais de ensino para pessoas autodeclaradas negras e indígenas.

Vale destacar de início que toda ação afirmativa, em seu princípio filosófico, procura corrigir injustiças socialmente e historicamente construídas. No caso das ações voltadas para a questão das desigualdades étnico-raciais, elas podem ser de três tipos: aquelas que objetivam reverter a representação negativa em espaços sociais de prestígio e poder; aquelas que visam promover igualdade de oportunidades sociais, econômicas e culturais; e aquelas que se destinam a combater o preconceito e o racismo. Em nosso caso, podemos afirmar que as cotas para as instituições federais de educação atendem, simultaneamente, aos três tipos supracitados. De tal modo, são uma das ações afirmativas mais complexas e, ao mesmo tempo, mais completas. Essa característica demanda também um grande número de pesquisas para acompanhar seu andamento, seus efeitos e seus resultados. Foi dessa demanda que surgiu o presente trabalho.

Em termos amplos, é preciso ter em mente que para se entender a necessidade e o fundamento de uma ação afirmativa é mister que se compreenda profundamente o contexto e a realidade social do país em questão, conhecendo amplamente o histórico que precedeu a instituição de tal política. É o caso explícito do Brasil, onde uma história de quase quatro séculos de escravidão encravou em nossa sociedade um "racismo estrutural”, como pensa Almeida (2018), que gerou índices sociais altamente desfavoráveis da população nãobranca, quando comparada à população branca. Tais índices vão desde expectativas de vida, moradia, nível de renda, acesso à saúde, empregabilidade, vulnerabilidade à violência e acesso à educação profissional e superior, sendo o último item o objeto sobre o qual nos debruçamos a pesquisar.

Para que a política pública em debate, cotas nas instituições federais de ensino, tenha real eficácia, é preciso acompanhá-la. Há muitas possibilidades de realizar tal ação. Uma delas é a que aqui propomos: a análise do desempenho dos cotistas no IFRN/Campus Caicó, ingressantes no ano de 2014, com base nas notas/conceitos, nos dados de frequência, na evasão, na aprovação e reprovação de cotistas e não cotistas, comparando ambos os grupos e compreendendo se há diferenças, e, havendo, de que tipo são e, por fim, quais as possíveis causas e soluções.

A Lei de Cotas (Lei 12.711, de 29 de agosto de 2012) institui a reserva de vagas nas instituições de ensino superior, técnico e tecnológico do Brasil, de pelo menos $50 \%$ para alunos oriundos da rede pública de ensino, levando ainda em consideração a renda familiar bruta e a identificação étnico-racial. No Instituto Federal de Educação, Ciência e 
Tecnologia do Rio Grande do Norte - IFRN tal política de inclusão social já vem ocorrendo desde de 1994, quando houve a aplicação do Pocefet, atual Proitec (Programa de Iniciação Tecnológica e Cidadania $)^{6}$, que já previa o deslocamento de vagas para alunos que tinham concluído o Ensino Fundamental em escolas públicas. É, nesse sentido, a partir da implementação da Lei de Cotas (BRASIL, 2012), que, ainda em 2012, o IFRN foi pioneiro na aplicação integral do texto da lei, abrindo vagas para candidatos com renda familiar bruta de até 1,5 salários mínimos e autodeclarados pretos, pardos e indígenas conforme o Edital nº. 03/2012-PROEN/IFRN.

Nesse contexto, as ações afirmativas que surgiram como um agente de combate à desigualdade de escolarização, marcante na população brasileira, e embasadas em índices sociais e econômicos e em estudos de décadas, passam a ser alvo de críticas na mídia, na sociedade e no âmbito político-partidário, fundamentadas por suposições acerca do "mérito" dos alunos cotistas e de uma "previsível" queda abrupta nos índices de desempenho acadêmico e na qualidade das instituições educacionais, uma vez que, devido às cotas, as instituições de ensino teriam de supostamente nivelar por baixo suas avaliações. Trata-se, com clareza, de um discurso de manutenção dos privilégios e de negação da ampliação da oferta de vagas nas instituições federais de ensino, historicamente dominadas por um grupo específico e que jamais apresenta dados concretos e fundamentados para embasar sua tese.

Foi também na esteira dessas disputas que a pesquisa aqui proposta se desenvolveu, esperando que por meio do levantamento de dados relacionados ao desempenho acadêmico dos alunos cotistas e não cotistas, o debate se desloque do lugar dos preconceitos e das suposições e coloque-se no debate e no conhecimento de dados e da realidade.

Desde o início, os pesquisadores envolvidos neste trabalho acreditavam que, por meio dele, seria possível contestar alguns desses discursos sem fundamentação e validar a implementação da política de cotas, caracterizando-a de fato como um marco do combate às desigualdades educacionais no Brasil.

A escolha do campus Caicó do IFRN se deu mediante a possibilidade de acompanhamento mais próximo dos discentes pela equipe de trabalho que compõe este estudo, visto que todos os pesquisadores têm, ou tinham na época de sua realização, vínculos com o referido campus. Além disso, espera-se que por meio da compilação dos dados levantados ocorram, não neste artigo, mas no âmbito do funcionamento da instituição pesquisada, proposições para ações de inclusão étnico-

\footnotetext{
${ }^{6} \mathrm{O}$ Programa de Iniciação Tecnológica e Cidadania é um curso na modalidade à distância voltado para alunos do nono ano da rede pública de ensino. O programa prepara os estudantes por meio de livro, de fascículos e de tele aulas para o ingresso no ensino técnico integrado ministrado pelo IFRN. Disponível em: https://portal.ifrn.edu.br/campus/reitoria/processos-seletivos. Acesso em 29/6/2020.
} 
raciais associadas a práticas educativas, contemplando um melhor atendimento às necessidades dos alunos cotistas, cumprindo assim os objetivos sociais e educacionais pensados quando houve a formulação da Lei de Cotas (Lei 12.711, de 29 de agosto de 2012).

\section{FUNDAMENTAÇÃO TEÓRICA}

Para articular uma pesquisa que buscou compilar e analisar o desempenho acadêmicoeducacional de alunos que ingressaram no IFRN/Campus Caicó por meio de uma política pública de combate às desigualdades raciais e educacionais, mais adequadamente chamada pelos estudiosos de ação afirmativa, é preciso entender com precisão os fundamentos de tal política, amparando teoricamente a necessidade e os fundamentos do presente estudo. Nas palavras de Scott (2005), renomada estudiosa e teórica das discussões norte-americanas sobre ações afirmativas, uma das premissas da ação afirmativa é "uma visão de justiça social”:

Essa visão preferia a inclusão à discriminação, mesmo se isso significasse a perda de privilégios tradicionais para alguns indivíduos. Ela endossou a igualdade de oportunidades e algumas de suas implicações niveladoras: comunidades mais homogêneas e menos hierarquicamente organizadas em termos de gênero e de raça (SCOTT, 2005, p. 5).

Segundo Guimarães (1999), eminente estudioso de políticas públicas no campo das relações étnico-raciais no Brasil, ações afirmativas são programas e/ou ações que promovem, ou que buscam promover, oportunidades para algumas pessoas, tomando por base seu pertencimento a um grupo específico. Em nosso caso, essas pessoas são aquelas que no senso populacional e nas pesquisas sobre indicativos sociais compõem o grupo de negros e indígenas. Lembrando que, em Ciências Sociais e Políticas Públicas, o conceito de "negro" inclui todos aqueles autodeclarados pretos e pardos, entrando aí o amplo gradiente de cores popularmente tratado como "moreno", "mulato”, entre outras inúmeras denominações.

Do ponto de vista teórico, na trilha de Guimarães (1999), buscando referenciais desde as primeiras discussões sobre ações afirmativas nos Estados Unidos da América na década de 60 do século passado, passando pelas discussões no âmbito do Direito que se deu na Suprema Corte americana, e que depois se espraiou para um amplo debate na Filosofia, nas Ciências Sociais e na Política em todo o Ocidente, são imaturos e ingênuos quaisquer debates sobre ações afirmativas, tais como as cotas, quando realizados com base em pressuposições e não em estudos sérios de centenas de profissionais que se dedicam à problemática das desigualdades étnico-raciais em vários países há décadas. 
Uma ação afirmativa não pode ser encarada como um benefício ou um privilégio, visto que se trata precisamente do contrário: ela é instituída quando se possui dados concretos, quantitativos e qualitativos, que revelam um histórico de injustiças, resultando em direitos negados a um determinado segmento populacional. Logo, em vez de privilégio, ela surge para quebrar com privilégios já existentes. Como afirmou Guimarães:

Apesar de não parecer claro ao senso comum, o princípio da ação afirmativa encontra seu fundamento na reiteração do mérito individual e da igualdade de oportunidades como valores supremos: a desigualdade de tratamento no acesso aos bens e aos meios justifica-se, apenas, como forma de restituir a igualdade de oportunidades, e, por isso mesmo, deve ser temporária em sua utilização, restrita em seu escopo, e particular em seu âmbito. Enfim, a ação afirmativa, sob esta ótica não reificada, é vista como um mecanismo, um artifício, para promover a equidade e a integração sociais (GUIMARAES, 1999, p. 181).

Nunca é demais relembrar que a desigualdade educacional entre pessoas brancas e nãobrancas, no Brasil, é gritante e é acessível a qualquer cidadão que queira conferir os dados que a explicam, seja através do senso do IBGE (Instituto Brasileiro de Geografia e Estatística), do PNAD (Pesquisa Nacional de Amostra por Domicílios), Ipea (Instituto de Pesquisa Econômica Aplicada,) ou até da extinta Seppir (Secretaria de Políticas de Promoção da Igualdade Racial), que tinha status de ministério e que realizou diversos levantamentos sobre desigualdades raciais. Foi com base em todo esse arcabouço de dados e pesquisas, e em décadas de estudos sobre relações raciais no Brasil, que foi instituída a Lei nº 12.711/2012, com o objetivo central de combater desigualdades raciais por meio do acesso à educação.

Todavia, para além do acesso às universidades e aos institutos federais, para respaldar, e, principalmente, aprimorar uma dada política pública é mister que haja trabalhos de acompanhamento e de análise sobre ela, como já foi aqui indicado. Foi nesse ponto que esta pesquisa se situou, pois se constata cotidianamente a produção de uma série de discursos não embasados em pesquisas amostrais que instituem preconceitos ou noções vazias sobre a presença em maior número dos sujeitos que formam o público-alvo das cotas étnico-raciais instituídas pela Lei n 12.711/2012, já comentada acima. Jocélio Teles dos Santos e Dalcele Mascarenhas de Queiroz (2014) pontuaram com exatidão essa questão:

No debate sobre as ações afirmativas nas universidades brasileiras o argumento sobre mérito é sempre recorrente. Os alunos oriundos das escolas públicas e aqueles que ingressaram através do sistema de cotas não conseguiriam ter um bom desempenho, principalmente nos cursos mais concorridos e, portanto, mais prestigiados na sociedade brasileira. A consequência seria o déficit no rendimento das disciplinas, e professores tendo que "nivelar por baixo" as suas avaliações. Como já foi apontado, trata-se de uma crítica programática (Filho et alli) em que se questiona o critério operacional amparado no discurso da meritocracia. Ou seja, haverá queda na qualidade de ensino, aumento da evasão 
e uma formação deficiente de profissionais. É necessário salientar que este argumento não está presente somente no ambiente acadêmico, posto que aparece em debates na mídia e em cartas de leitores publicadas em jornais diários (QUEIROZ; SANTOS, 2014, p. 7).

Assim, os pesquisadores mencionados assinalam a necessidade de se "dispor de dados para que a avaliação do novo sistema seja deslocada do 'achismo’ e das representações ideológicas presentes no debate, contrárias às ações afirmativas para estudantes oriund os da escola pública, negros e indígenas" e de ser começar a trabalhar na "avaliação do impacto das ações afirmativas nos espaços acadêmicos. Afinal, como sustentar um argumento convincente a não ser pelo exercício analítico?" (QUEIROZ; SANTOS, 2014). Cabe ressaltar que ambos já iniciaram esse trabalho na Universidade Federal da Bahia, analisando os dados dos alunos cotistas no ensino superior, e já nos apresentam alguns de seus resultados, destacando:

Ao contrário da expectativa daqueles que se mostravam resistentes à implantação do referido sistema [de cotas], temendo uma desqualificação do ensino pelo ingresso de estudantes supostamente despreparados na Universidade, o exame do desempenho dos estudantes que ingressaram na UFBA pelo sistema de cotas revela resultados bastante animadores, nos cursos das diversas áreas de conhecimento (QUEIROZ; SANTOS, 2014, p. 11).

De tal modo, a avaliação aqui proposta, e teoricamente embasada, visou contribuir para que a ação afirmativa instituída por lei, como política pública de Estado, a qual os pesquisadores defendem como política de correções de desigualdades, venha a ter real eficácia e índices concretos quando for objeto de debate, esta pesquisa servindo, portanto, como suporte para análises da referida política de inclusão e referência para o debate público.

Cremos, dessa maneira, estar dando uma parcela de contribuição para a efetiva realização do que intenciona a política pública que estabeleceu as cotas étnico-raciais, que é diminuir as desigualdades e criar condições iguais de oportunidades para todos, visando, em última instância, romper com o ciclo vicioso da reprodução das desigualdades no âmbito da educação, já evidenciado há décadas por Bourdieu (2008).

\section{METODOLOGIA}

O processo metodológico da pesquisa, no que se refere à coleta de dados, iniciou-se com a consulta aos arquivos disponíveis na Secretaria Acadêmica do IFRN/Campus Caicó, que disponibilizou aos pesquisadores a lista de todos os alunos matriculados na modalidade 
Integrado no ano de 2014. Na lista havia informações como: curso, lista pela qual concorreu (cotistas, não cotistas etc.), dados locacionais e de contatos, origem escolar, situação etc. Os alunos que pertenciam às listas 2 e 4 , sendo estes, respectivamente, cotistas raciais declarados baixa renda e apenas cotistas raciais, foram separados e os seus dados, após coletados e tabulados, foram comparados com os demais. Tais informativos geraram muitos números e dados sobre desempenho acadêmico e permanência/evasão que, ao fim, foram transformados em gráficos, os quais são aqui apresentados.

Após separar esses dois grupos (cotistas étnico-raciais e demais selecionados), iniciou-se a coleta virtual de outros dados disponíveis no Suap (Sistema Unificado da Administração Pública), sistema que é utilizado pelos servidores e por alunos do IFRN. Coletaram-se os níveis de frequência nos diários de classe dos professores, em porcentagem dos alunos e fez-se uma média aritmética para cada um. Em seguida, com base na média aritmética de cada aluno fez-se uma média aritmética geral, ou seja, de todas as frequências de cada grupo de discentes (cotistas étnico-raciais e demais selecionados). Após discussão entre os pesquisadores, decidiu-se que seriam levadas em consideração, para construção de gráficos e análises, apenas as disciplinas propedêuticas, sendo estas: Arte, Língua Portuguesa, Língua Espanhola, Filosofia, Sociologia, Matemática, Educação Física, Química, Física, Geografia, História, Biologia e Inglês. A escolha justificou-se pelo fato de serem as únicas disciplinas comuns a todos os alunos dos quatro cursos técnicos, tendo em conta que as disciplinas do eixo técnico são únicas em cada um dos cursos (Cursos Técnicos Integrados em Informática, Eletrotécnica, Vestuário e Têxtil), o que restringiria as comparações.

Objetivando construir comparações mais específicas que viessem a apresentar indicadores precisos sobre a realidade do alunado do Campus Caicó, no que se refere à permanência e ao êxito acadêmico, os grupos de discentes foram separados por seus respectivos cursos. Iniciou-se a coleta das notas encontradas no histórico escolar de cada aluno, sendo estas calculadas por uma média aritmética com a finalidade de reduzi-las a apenas um valor. Em seguida, as notas dos alunos foram tabuladas e novamente aplicadas à fórmula aritmética, gerando uma média de todos os demais selecionados e de cotistas étnico-raciais dos cursos de Eletrotécnica, Informática, Têxtil e Vestuário, permitindo comparação dos valores entre os grupos.

Dessa forma, para uma melhor análise e apresentação, os gráficos gerados pelo processo supracitado foram reduzidos em formato único. Assim, no novo comparativo foram levadas em consideração as médias gerais obtidas de cada curso, gerando um gráfico que apresenta uma comparação do desempenho íntegro dos cotistas étnico-raciais e dos demais selecionados. Além das notas, a quantidade de reprovações e de dependências também foi tabulada e comparada entre os grupos de alunos, como também entre os cursos. A partir daí o trabalho 
de coleta e de construção de dados encerrou-se e começaram a ser analisados, gerando os resultados que são apresentados a seguir na forma de gráficos.

Além da construção dos referidos gráficos, também tentamos construir dados qualitativos, buscando realizar entrevistas com o grupo de alunos cotistas. As entrevistas poderiam mostrar realidades que os números não mostravam, por exemplo, os motivos de dificuldades em alguma disciplina. Entretanto, sendo os referidos alunos já concludentes, foi muito difícil obter retorno dos contatos que fizemos. Assim, ao final, conseguimos nove entrevistas. Elas também compõem as análises e os resultados dessa pesquisa.

\section{RESULTADOS}

Inicialmente, faz-se necessária uma breve explicação acerca do processo seletivo para ingresso dos alunos do Ensino Médio Integrado (EMI). Embora a reserva de vagas (50\%) para estudantes oriundos de escolas públicas já viesse sendo aplicada no ano de 2014, o IFRN aplicaria pela primeira vez as cotas étnico-raciais conforme o estabelecido na Lei de Cotas (Lei 12.711, de 29 de agosto de 2012)

De acordo com o Edital nº 24/2013-PROEN/IFRN, a distribuição das vagas observou os seguintes critérios:

> $50 \%$ das vagas gerais contemplaram alunos com o melhor desempenho acadêmico no processo seletivo, independentemente de sua escola ser pública ou particular e de sua origem étnico-racial;

> $50 \%$ das vagas seriam destinadas aos alunos com o melhor desempenho acadêmico, oriundos de escolas públicas, considerando-se a diferenciação da renda per capita e da auto declaração dos candidatos como pretos, pardos ou indígenas (PPI). As vagas foram assim distribuídas:

a) Lista $1\left(\mathrm{~L}_{1}\right)$ - candidatos de qualquer etnia com renda menor que 1,5 salário mínimo;

b) Lista 2 (L2) - candidato autodeclarado PPI com renda menor que 1,5 salário mínimo;

c) Lista 3 (L3) - candidato de qualquer etnia e qualquer renda;

d) Lista 4 (L4) - candidato de qualquer renda autodeclarado PPI.

Passemos à análise dos resultados obtidos na pesquisa, aqui expressos nos gráficos que seguem: 
Gráfico 1 - Alunos ingressantes no EMI, em 2014.



Fonte - Elaboração dos autores. IFRN, 2014.

Observando o quantitativo geral dos alunos ingressantes nos cursos técnicos integrados do campus Caicó, naquele ano, vimos, de início, um dado curioso: o curso técnico em Têxtil não preencheu as vagas da cota, especialmente a L2. Uma possível explicação para a ausência de inscritos seria por ser o primeiro ano da existência do curso ou pelo desconhecimento da lei pelo público que procurou se inscrever no referido curso, bem como o fato de a lei de cotas estar sendo aplicada pela primeira vez nos processos seletivos do IFRN. De acordo com o Gráfico 2, vê-se que o percentual geral de alunos cotistas PPI atingiu apenas $27 \%$ do total. Visto se tratar de coleta no sistema, não é possível afirmar com total precisão os motivos para tanto.

Gráfico 2 - porcentagem de quantitativos de alunos ingressantes, em 2014.



Fonte - elaboração dos autores. IFRN, 2014. 
No cruzamento dos dados referentes à auto declaração dos cotistas que constam na inscrição no processo seletivo com os dados declarados por estes na matrícula, percebe-se uma discrepância, conforme fica explícito nos gráficos 3 e 4, em que a quantidade de pretos, pardos e indígenas não corresponde a apresentada no Gráfico 1. Tomemos por base o curso de Eletrotécnica, por exemplo. Vemos que no Gráfico 1 os cotistas PPI somam dez alunos e no Gráfico 2 apenas a metade desse total se autodeclarou como pardo e nenhum como negro. A mesma tendência se repete nos demais cursos.

Gráfico 3 - Cotistas autodeclarados PPI da L2 e L4, em 2014.

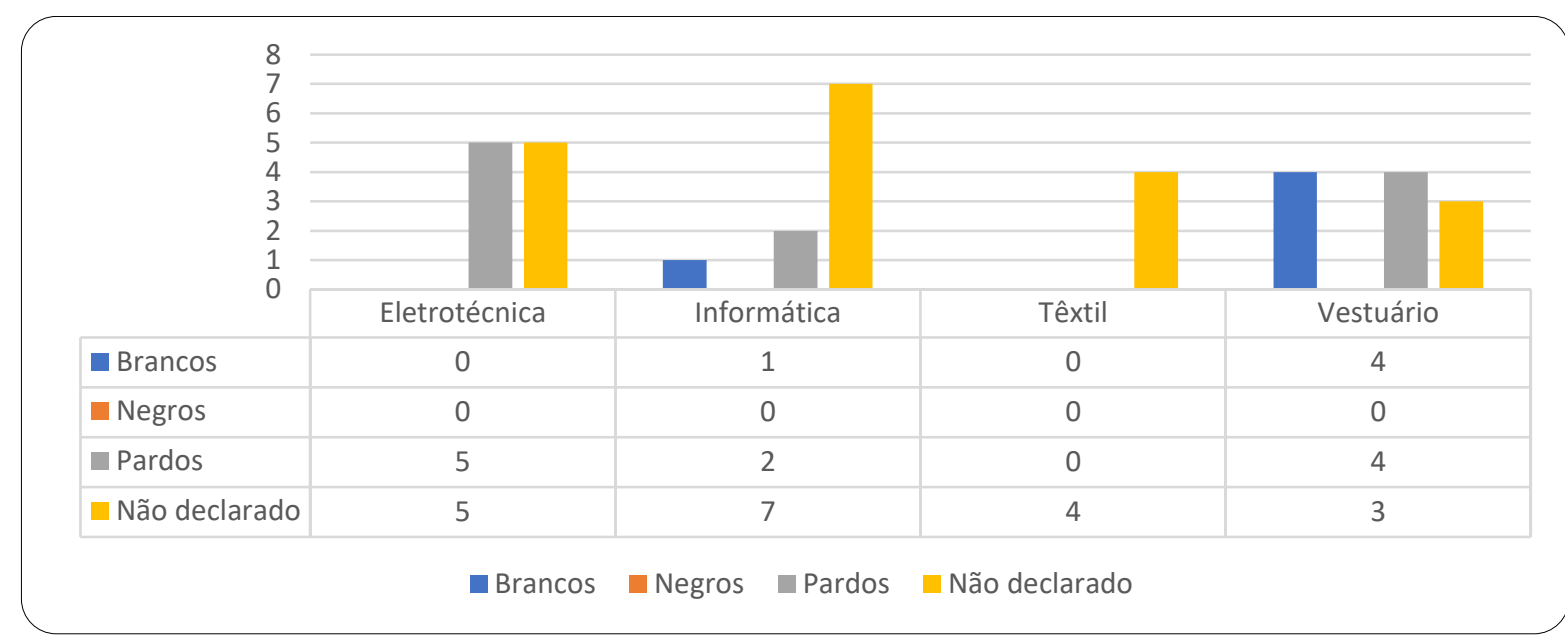

Fonte - elaboração dos autores. IFRN, 2014.

Constata-se que a maioria dos alunos, mesmo os cotistas, não se preocuparam em manter sua auto declaração, parecendo dar-lhe pouca importância, a não ser no processo seletivo. Isso parece indicar que a opção pela auto declaração apenas serviu para atender a uma necessidade imediata, a possibilidade de usufruir da cota, sem, no entanto, suscitar de modo mais abrangente questões de identidade.

De acordo com o Gráfico 4, entre os alunos selecionados na lista geral e nas listas 1 e 3, o percentual de alunos não declarados somados aos autodeclarados como brancos não condizem com os dados apresentados no Gráfico 1. 
Gráfico 4-Alunos não cotistas PPI selecionados no processo seletivo, em 2014.

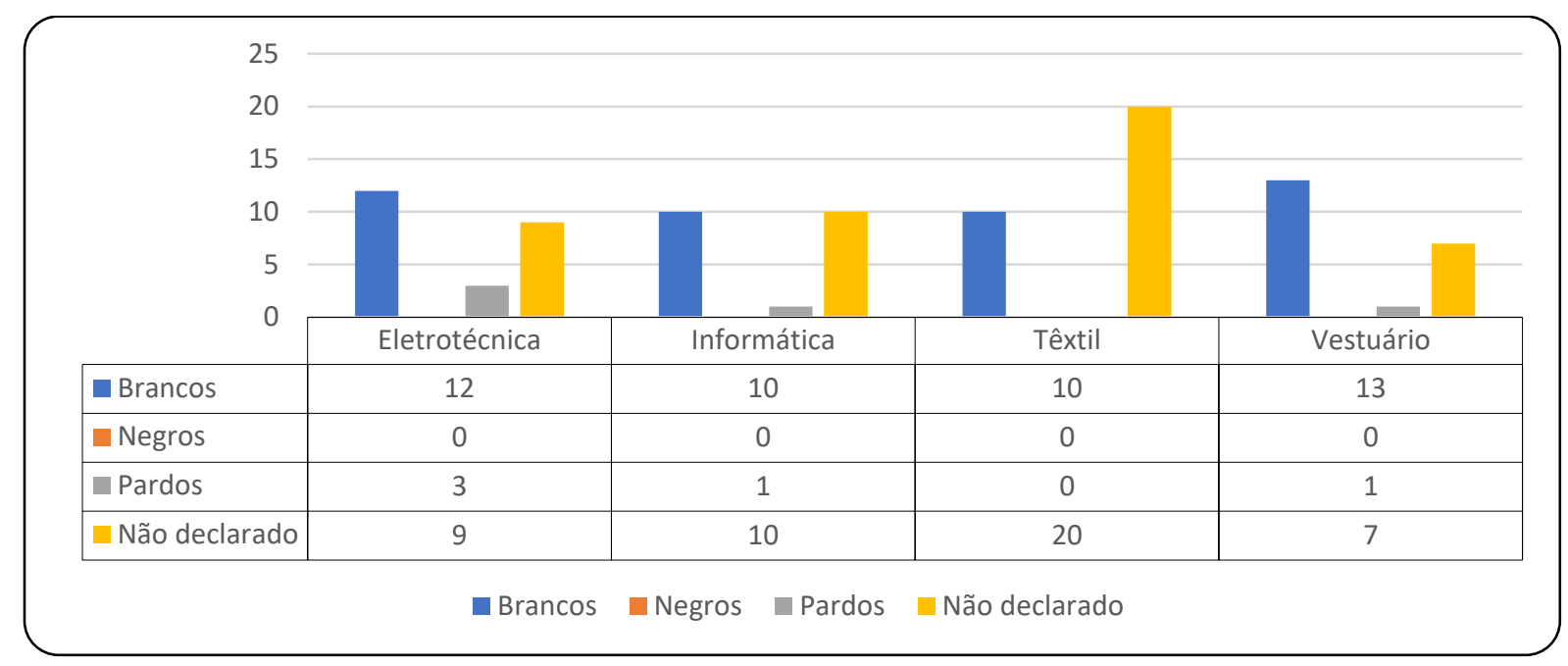

Fonte - elaboração dos autores. IFRN, 2014.

Em relação ao desempenho acadêmico, objeto desta pesquisa, ao compararmos os dados dos alunos cotistas e dos não cotistas percebemos uma pequena diferença em favor dos não cotistas. Essa diferença é mais acentuada no curso de Vestuário e de Informática. Nos cursos de Eletrotécnica e de Têxtil parece-nos insignificante. Considerando os contextos de aprendizagem em que estiveram inseridos os cotistas e os não cotistas, a pequena diferença nos rendimentos indica que possíveis dificuldades enfrentadas, inicialmente, pelos cotistas e pelos supostos desníveis nas suas curvas de rendimento acadêmico não se constituíram como obstáculos insuperáveis. Dadas as condições objetivas de suas trajetórias acadêmicas anteriores, essas diferenças são até compreensíveis. O dado mais importante que isso nos parece suscitar é que, uma vez inseridos nas rotinas acadêmicas em iguais condições e podendo usufruir das mesmas oportunidades, os estudantes cotistas tenderam a apresentar resultados satisfatórios, reduzindo significativamente as diferenças oriundas do histórico de desigualdade social e escolar.

Nessa trilha, quando se considera o Índice de Rendimento Acadêmico (IRA), no geral, os não cotistas (Gráficos 6) apresentam rendimento apenas levemente superior aos cotistas (Gráficos 5). 
Gráfico 5 - Média do IRA dos cotistas por curso, em 2014.

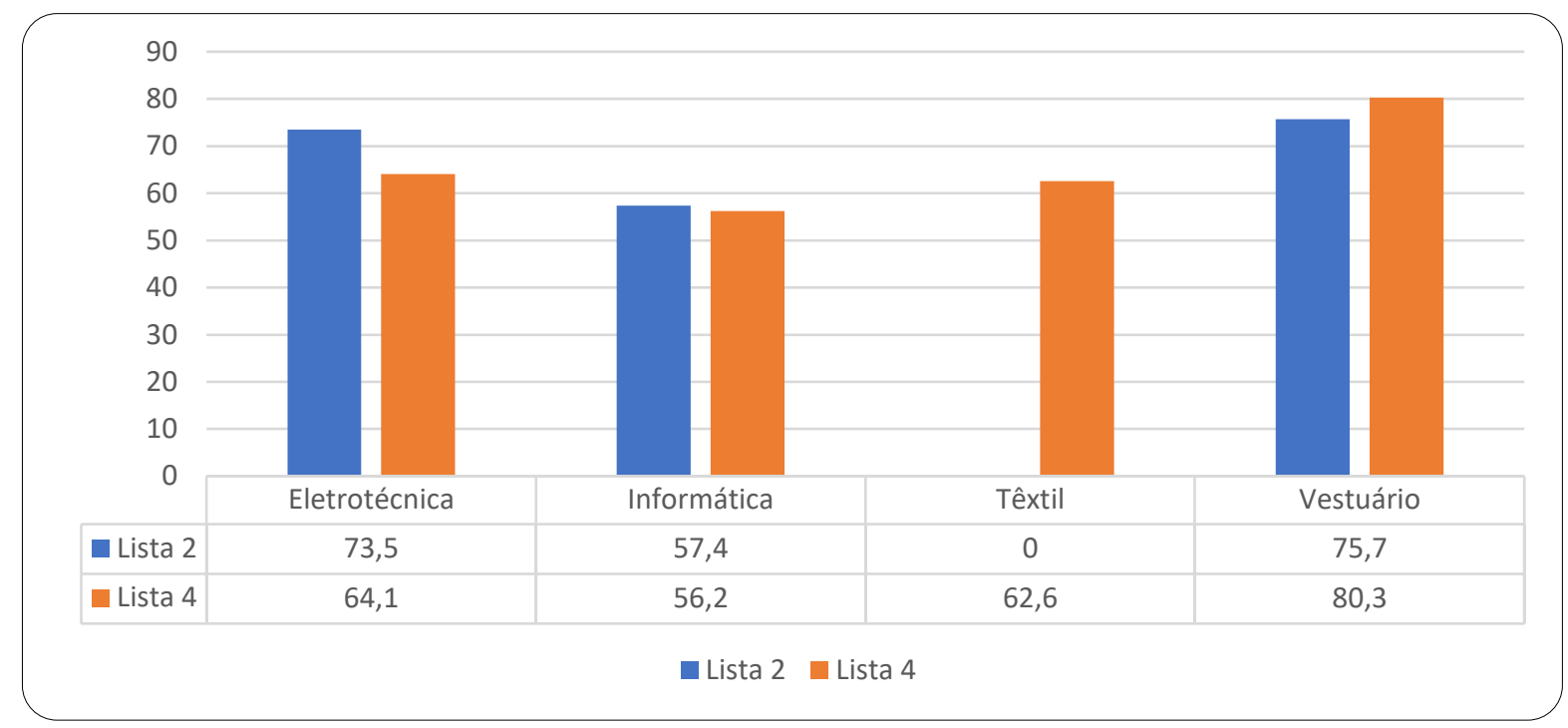

Fonte - elaboração dos autores. IFRN, 2014.

Conforme o Gráfico 5, o rendimento acadêmico dos cotistas PPI nas listas 2 e 4 apresentase com uma leve diferença. Possivelmente por conta das disparidades socioeconômicas, considerando que os selecionados da lista 2 declararam ter renda per capita inferior a 1,5 salário mínimo. No entanto, nos Cursos de Eletrotécnica e de Vestuário, os cotistas da lista 2 apresentam um rendimento acadêmico superior aos cotistas da lista 4. Não obstante, com exceção do curso de Vestuário, o desempenho acadêmico dos demais selecionados, coerente com as análises socioeconômicas, apresenta-se um pouco superior aos cotistas PPI, especialmente nos cursos de Informática e de Eletrotécnica, como se vê comparando os dois gráficos.

Gráfico 6 - Média do IRA dos demais selecionados por cursos, em 2014.

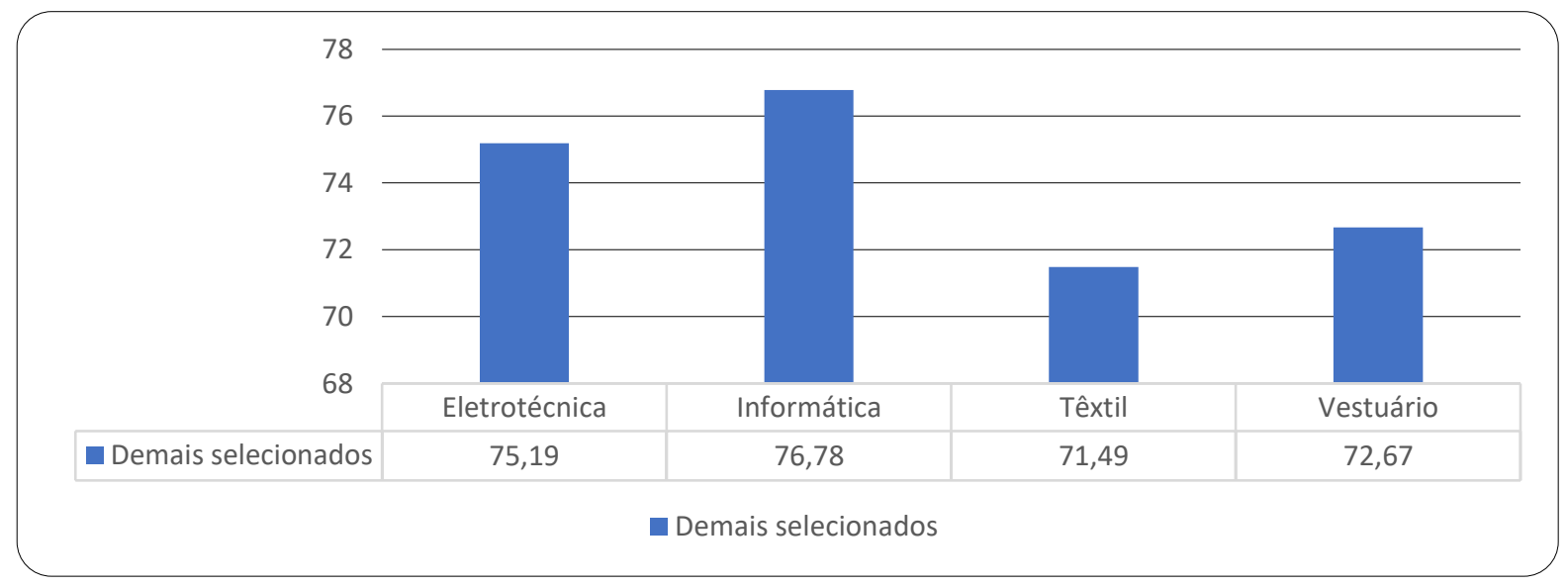

Fonte - elaboração dos autores. IFRN, 2014. 
Em relação aos quesitos de evasão, de jubilamento, de cancelamento e de conclusão entre os alunos matriculados, a pesquisa apresenta os seguintes resultados: os não-cotistas têm um índice menor de conclusão e uma maior quantidade de evasão. Por outro lado, os cotistas têm um índice bem maior de matrículas canceladas.

Gráfico 7 - Situação atual dos cotistas (após conclusão do curso), em 2014.



Fonte - elaboração dos autores. IFRN, 2014.

Gráfico 8 - Situação atual dos demais selecionados (após conclusão do curso), em 2014.

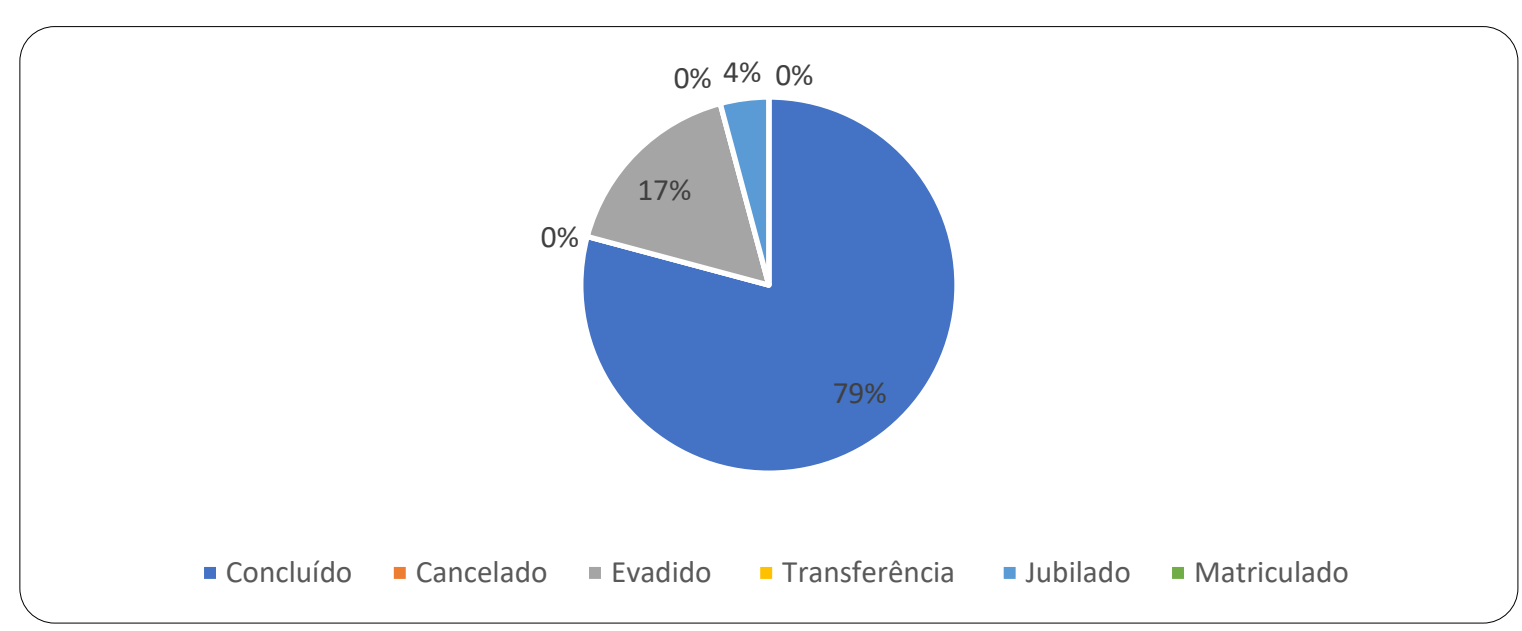

Fonte - elaboração dos autores. IFRN, 2014.

Um dado que chama a atenção se refere à incompatibilidade entre a cor declarada na hora da seleção e a declarada na hora da matrícula. Conforme se verifica no Gráfico 9, entre os cotistas das listas 2 e 4, aparecem quatro alunos que se autodeclararam brancos no curso de Vestuário e um no curso de Informática. Ademais, há um número significativo entre os não 
declarados, o que indica que embora se autodeclarem PPI por ocasião do processo seletivo, nem sempre o fazem no ato da matrícula.

Gráfico 9 - cotistas autodeclarados PPI no ato da matrícula, em 2014.

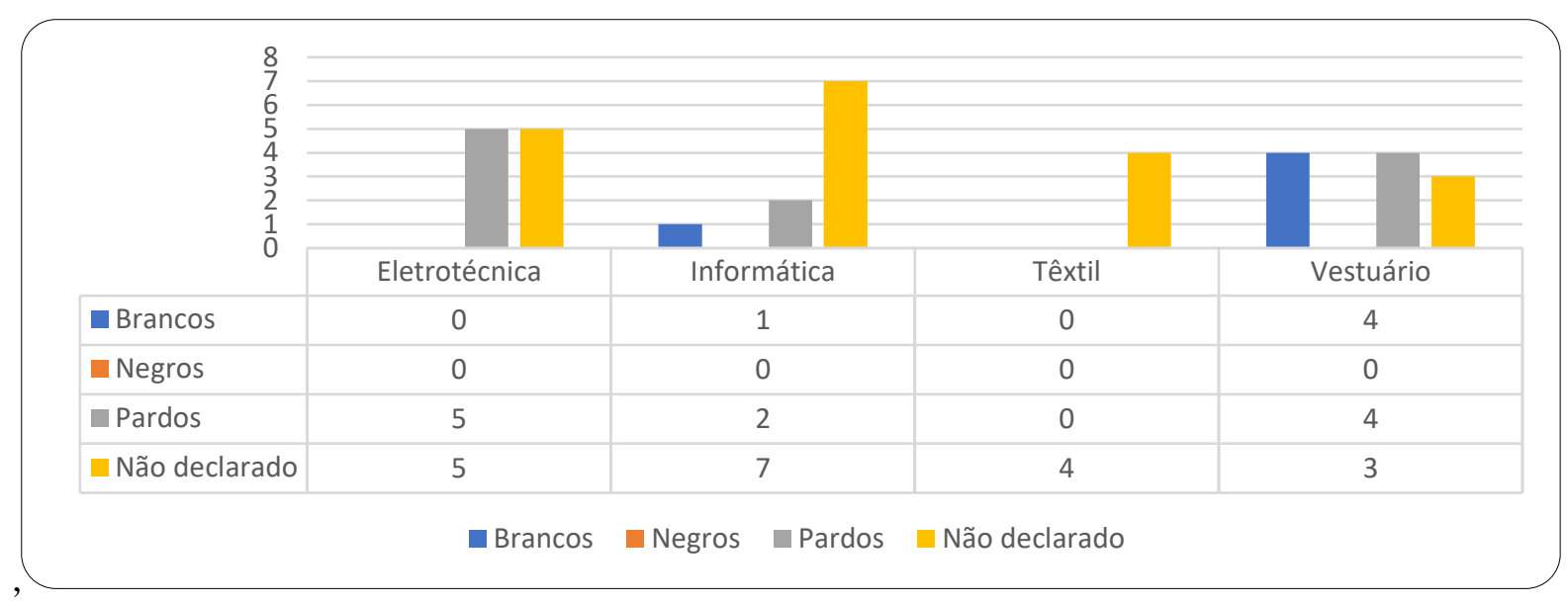

Fonte - elaboração dos autores. IFRN, 2014.

Entre os demais selecionados, o quantitativo de alunos autodeclarados é bem significativo, indicando que possivelmente o número de alunos PPI seja bem maior, uma vez que não se autodeclararam como brancos, mas também não afirmaram sua etnia/cor, o que pode sugerir o temor de se exporem ao preconceito, ou, mesmo, a ausência dessa auto afirmação identitária.

Gráfico 10 - alunos autodeclarados entre os demais selecionados, em 2014.

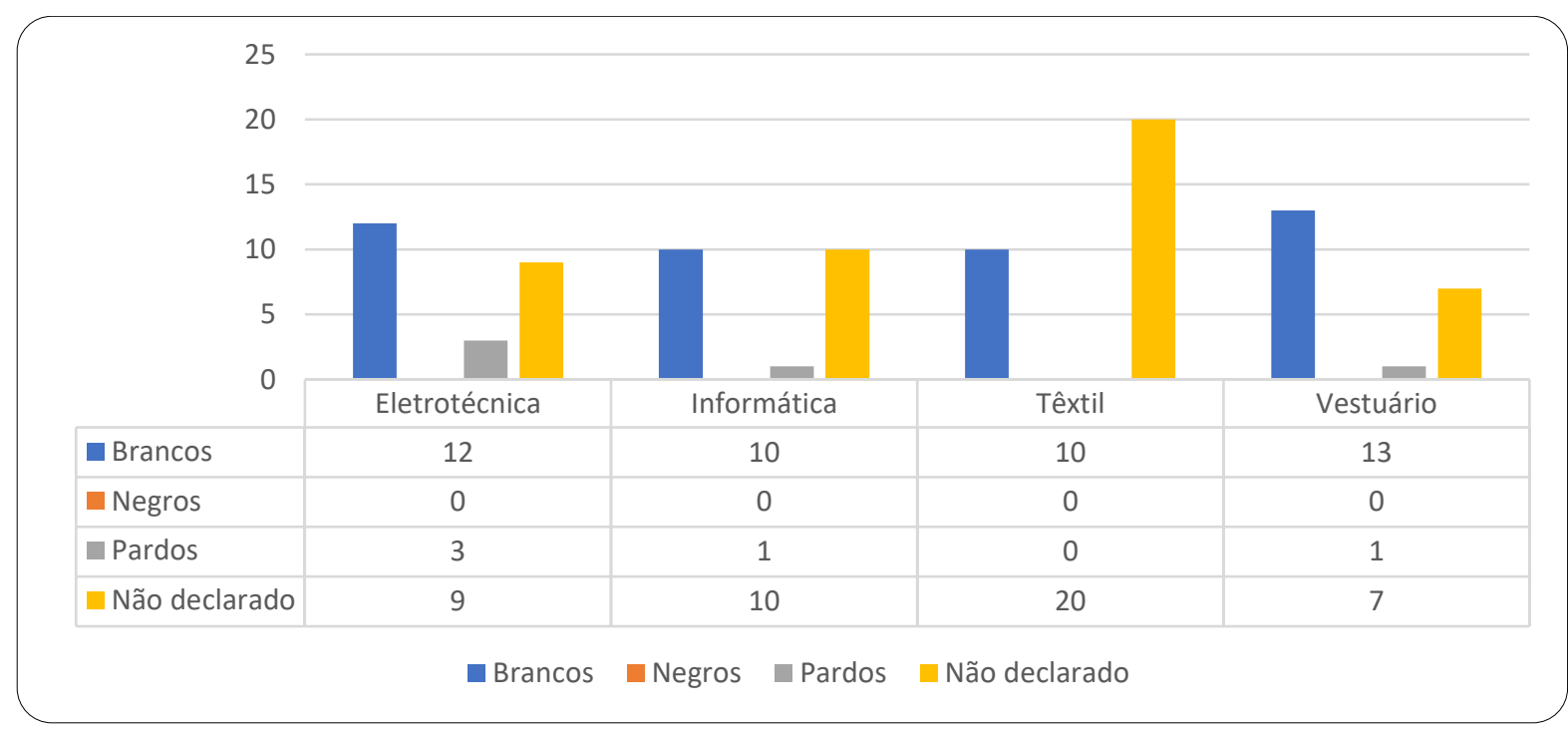

Fonte - elaboração dos autores. IFRN, 2014. 
Sobre a frequência/assiduidade dos alunos cotistas e não cotistas não foi possível verificar diferenças relevantes, sendo que em alguns casos há uma leve vantagem dos cotistas em relação aos demais selecionados, conforme podemos constatar no Gráfico 11.

Gráfico 11 - Frequência dos alunos cotistas e não cotistas, em 2014.



Fonte - elaboração dos autores. IFRN, 2014.

Por fim, temos os gráficos com maior representatividade no quesito desempenho acadêmico se considerarmos a grande quantidade de informações relacionadas ao aproveitamento das disciplinas. O levantamento foi realizado considerando todas as disciplinas de formação geral que, portanto, são comuns a todos os cursos. Os gráficos a seguir fazem uma comparação do percentual alcançado pelos alunos cotistas e pelos alunos não cotistas. 
Gráfico 12 - Desempenho acadêmico no Curso Técnico Integrado em Eletrotécnica, em 2014.

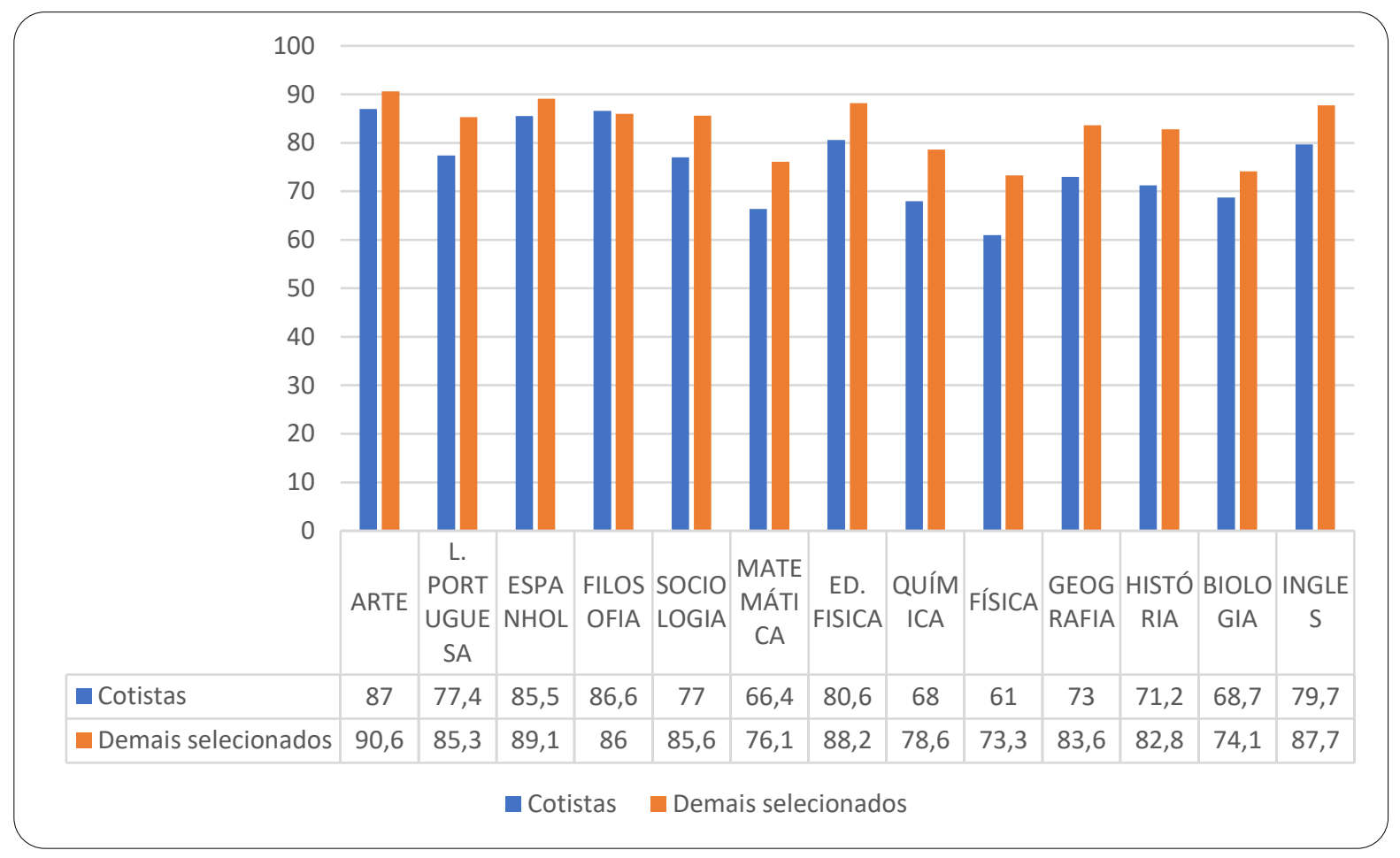

Fonte - elaboração dos autores. IFRN, 2014.

Gráfico 13 - Desempenho acadêmico no Curso Técnico Integrado em Informática, em 2014.

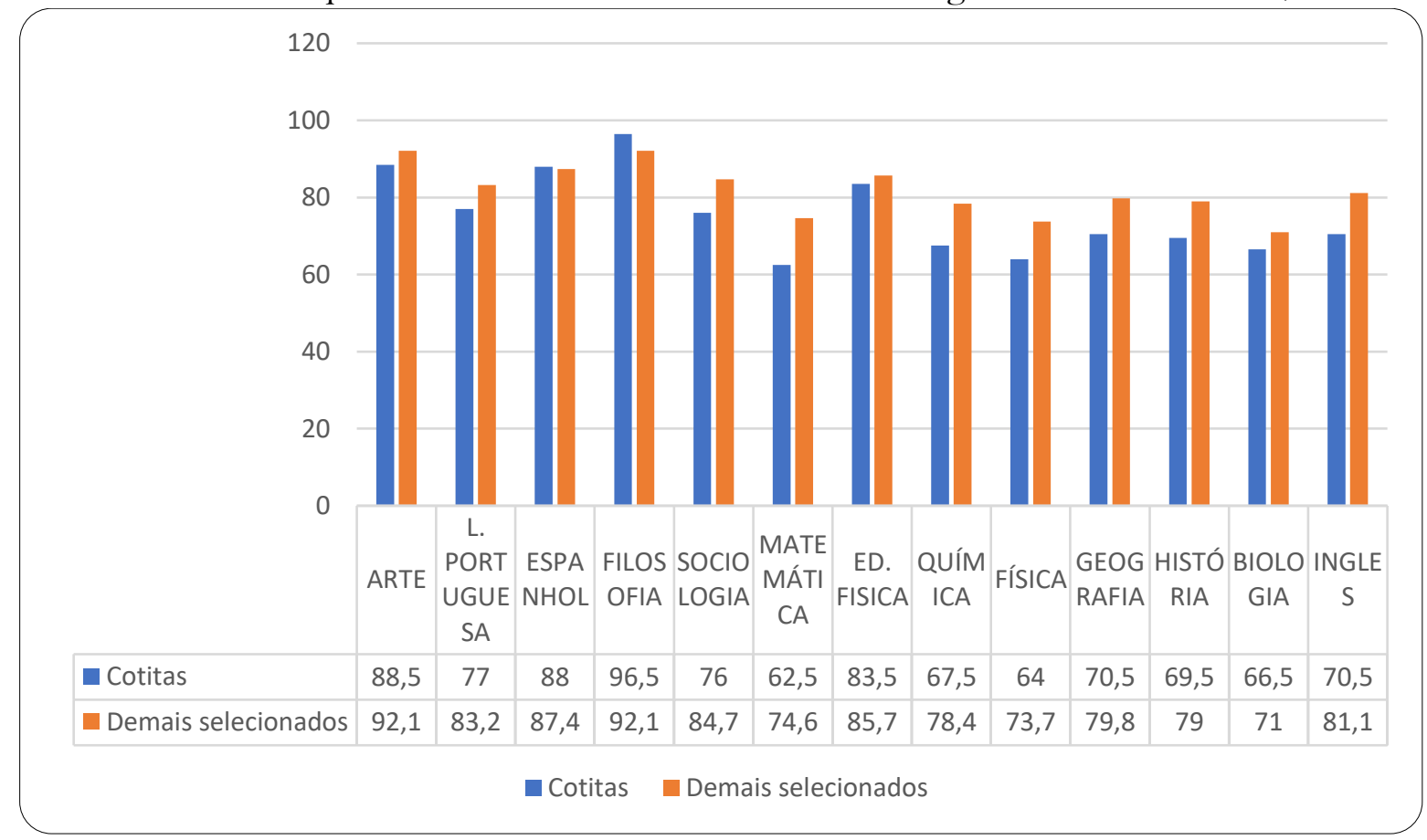

Fonte - elaboração dos autores. IFRN, 2014. 
Gráfico 14-Desempenho acadêmico no Curso Técnico Integrado em Têxtil, em 2014.

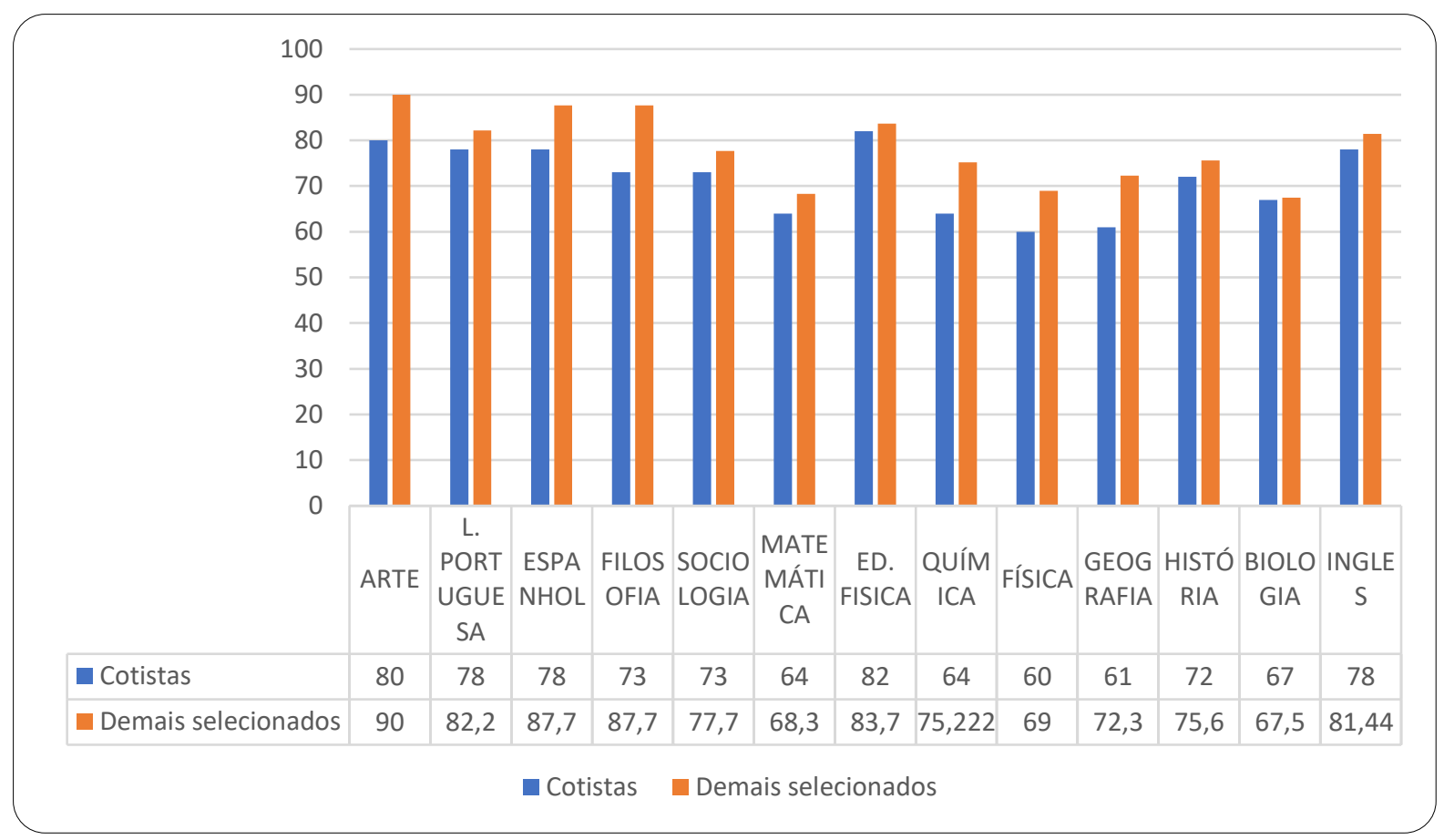

Fonte - elaboração dos autores. IFRN, 2014.

Gráfico 15 - Desempenho acadêmico no Curso Técnico Integrado em Vestuário, em 2014.

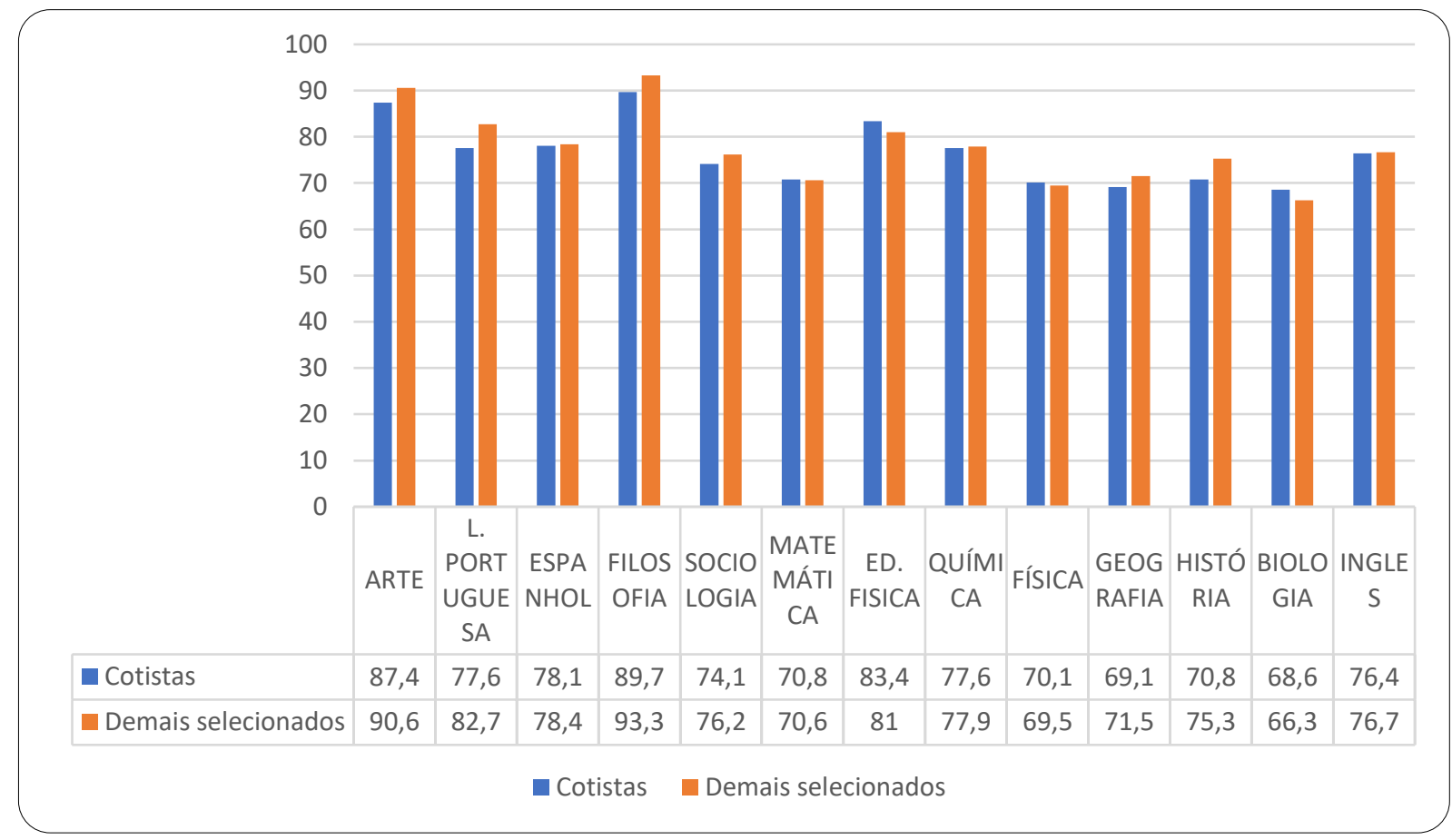

Fonte - elaboração dos autores. IFRN, 2014. 
A análise dos resultados permite-nos inferir que:

a) Nas disciplinas da área de Ciências da Natureza, como Física e Química, há uma discrepância entre o desempenho dos cotistas e dos não cotistas, assim como a área de Linguagens, como Língua Portuguesa, embora esta seja um pouco menor (em torno de quatro a oito). Tal diferença aparece em todos os cursos (Gráfico 16).

b) A área de Matemática apresenta disparidades de até dez pontos (idem).

c) A área de Ciências Humanas (História e Geografia) apresenta diferenças de até dez pontos (ibidem).

Obviamente, essas diferenças foram identificadas em quase todas as disciplinas, mas optou-se por destacar as mais significativas. Em algumas disciplinas, a diferença realmente inexiste. É importante considerar que o cálculo foi realizado utilizando uma média geral. Não foram consideradas as diferenças individuais.

Gráfico 16 - Rendimento geral de cotistas e demais alunos selecionados, em 2014.

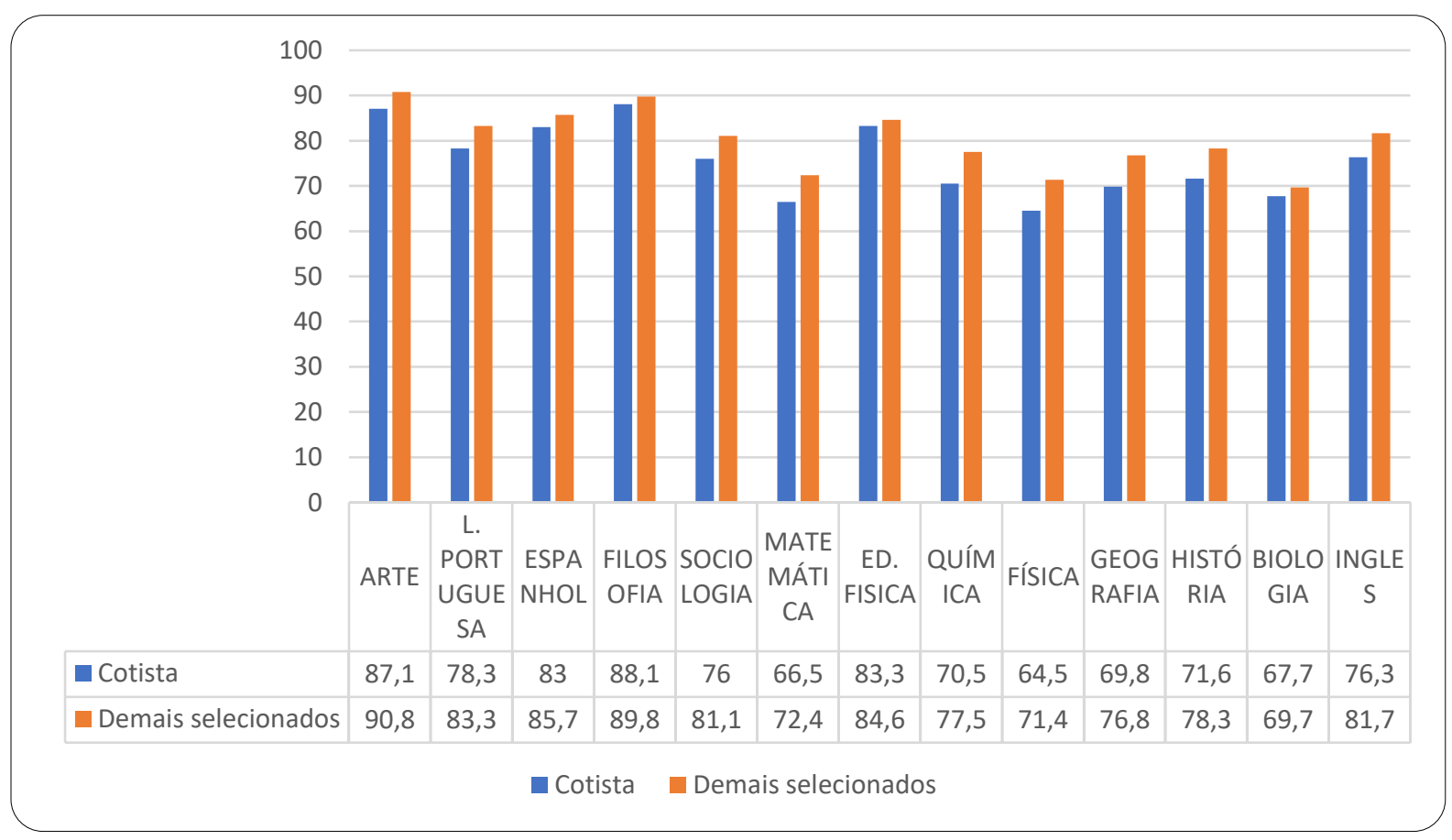

Fonte - elaboração dos autores. IFRN, 2014.

Apesar das diferenças apresentadas, considera-se que o rendimento geral dos alunos cotistas, especialmente nas séries finais do curso, apresenta-se muito satisfatório. Conforme se pode conferir no Gráfico 16, o Curso Técnico Integrado em Vestuário apresenta o resultado mais equilibrado. 


\section{REFERÊNCIAS}

ALMEIDA, Silvio Luiz de. O Que É Racismo Estrutural? Belo Horizonte: Letramento, 2018.

BOURDIEU, Pierre; PASSERON, Jean-Claude. A Reprodução. Petrópolis, RJ: Vozes, 2008 (tradução: Reynaldo Bairão).

BRASIL Decreto ${ }^{\circ}$ 7.824, de 11 de outubro de 2012. Regulamenta a Lei $n^{\circ} 12.711$, de 29 de agosto de 2012, que dispõe sobre o ingresso nas universidades federais e nas instituições federais de ensino técnico de nível médio. Disponível em: http://www.planalto.gov.br/ccivil 03/ Ato2011-2014/2012/Decreto. Acesso em 29/06/2020.

GOLDENBERG, Mirian. A Arte de Pesquisar: como fazer pesquisa. $11^{\text {a }}$ ed.-Rio de Janeiro: Record, 2009.

GUIMARÃES, Antônio Sérgio Alfredo. Racismo e Anti-Racismo no Brasil. São Paulo: Editora 34, 1999.

INSTITUTO FEDERAL DE EDUCAÇÃO, CIÊNCIA E TECNOLOGIA DO RIO GRANDE DO NORTE. Projeto Político-Pedagógico do IFRN: uma construção coletiva: documentobase/Instituto Federal de Educação, Ciência e Tecnologia do Rio do Norte. Natal: IFRN, 2012.

INSTITUTO FEDERAL DE EDUCAÇÃO, CIÊNCIA E TECNOLOGIA DO RIO GRANDE DO NORTE. Edital N ${ }^{o}$. 03/2012-PROEN/IFRN. Disponível em: https://portal.ifrn.edu.br. Acesso em 2906/2020.

INSTITUTO DE PESQUISA ECONÔMICA APLICADA (IPEA). Situação Social da População Negra Por Estado. Instituto de Pesquisa Econômica Aplicada; Secretaria de Políticas de Promoção da Igualdade Racial. Brasília: IPEA, 2014.

QUEIROZ, D. M.; SANTOS, J. T. dos. Sistema de Cotas: um debate. Dos dados à manutenção de privilégios e de poder. Educação e Sociedade, Campinas, v. 27, n. 96, out. 2006. Disponível em: < http://www.scielo.br/scielo.php?pid=So10173302006000300005\&script $=$ sci_arttext $>$. Acesso em: 24 nov. 2014. DOI: https://doi.org/10.1590/s0101-73302006000300005.

SCOTT, Joan W. O enigma da igualdade. Revista Estudos Feministas, vol, nº 3, set.-dez. 2005, pp.11-30. 